EISSN: 2706-7955 ISSN: 2077-4605

DOI: $10.36632 /$ mejar/2021.10.4.82

Journal homepage: www.curresweb.com

Pages: 1250-1258

\title{
Some Traits of Parks Visitors in Sudan
}

\section{Suad K. Ahmed and Mahmood E. Yagi}

College of Agricultural Studies, Sudan University of Science and Technology, Khartoum North, Sudan. Received: 13 Sept. 2021

Accepted: 20 Nov. 2021

Published: 25 Nov. 2021

\begin{abstract}
Recently, more attention has been directed towards the important roles of urban parks as an essential constituent for development of the overall quality of the urban life. Besides many environmental and economical roles, urban parks provide important social, health, aesethetic, recreational and psychological benefits to human societies. In Sudan, the population explosion in Khartoum and the capitals of the different states necessitate the provision of urban parks to meet the popular need for such services. Public perception surveys can enable green infrastructure managers to use this information in the urban planning framework. The main concern of this paper is to address studying of some traits of parks visitors in El Hurea Yard Park in Khartoum city, the capital of the Sudan. Results confirmed that: Two third of park visitors are males, more than (90\%) of them are less than 35 years and (97\%) come in group to visit the park. It is also shown that, more than 4 in 5 respondents were: Born in urban areas, reside in Khartoum city, bachelor and university educated. The results declared that, the two main goals for visiting the park are: Enjoying the outdoors or nature and meeting relatives, friends and neighbors.
\end{abstract}

Keywords: Urban Parks, visitor traits, Respondents

\section{Introduction}

Alberta Culture and Tourism. Final Report. (2017) defined parks as: green areas or cultivated lands with few or no buildings within or adjoining a town, set aside for recreation and ornamental purposes. It may consist of trees, grassy areas, rocks, soil, buildings and other artifacts such as monuments, fountains or playground structures. Many parks have fields for playing sports such as soccer, baseball, football, and paved areas for games such as basketball. Parks may have trails for walking, biking and other activities. Urban parks may have benches for sitting, picnic tables and barbecue grills.

In the Netherlands, parks has a positive effect on the price of nearby commercial properties (Luttik, 2000). In Dallas, residents said that, the public green spaces running behind their back gardens as a major factor in their decision to move to the area. And that the value of their homes was higher because of the presence of the green spaces (Peiser, and Schwann, 1993). Residents agree to pay 20-40 percent more than the average price for a house with a view of a green area (Paraskevi, 2016). As parks in and around cities play an important role in influencing the prevailing climatic conditions, through thier plants which provide shade, reduce temperature, softening the air, purifying it, and protecting from pollution, sands and winds (Suad and Mahmoud, 2021). It is reported that, more than 4 in 5 people said that, parks and recreation is an important local government service. Furthermore, seventy-two percent of the American adults agreed that, they are more likely to vote for a local political leader who makes parks and recreation funding a priority (Robert and Wayne, 2017).

El Hurea Yard Park is considered as one of the most important landmarks of Khartoum, it is located in the heart of Khartoum city, north of Afra Mall and south of Khartoum International Airport, in a total area of 250 thousand square meter ( $25 \mathrm{hec}$.). The park was established in April 2015, owned by Government presentier, designed in natural design, positioned inside the city and the park open to visitors at night and early morning for walking and sport activities.

Corresponding Author: Suad K. Ahmed, College of Agricultural Studies, Sudan University of Science and Technology, Khartoum North, Sudan. E-mail: wahag606@gmail.com 


\section{Research Methodology}

To evaluate parks in Sudan, a questionnaire was designed. The population is the respondents (from park visitors) of El Hurea Yard Park. The population size is 100 respondents from El Hurea Yard Park. And the questionnaire used for analyses is 100 from the parks. This questionnaire included: Respondents' demographics mainly: gender, age, educational level, occupation, monthly income, marital status, place of birth, place of living, distance of respondents home from the park area, presence of public garden in respondents area, why respondents in Khartoum, division of respondents groups, what respondents do in the parks and frequency of visitations to the park. Data collected by off-line survey method (where the researcher distributed the questionnaire to the respondents by hand). The questionnaire forms were randomly distributed to the park visitors. Then it was statistically analyzed using SPSS computer package and the result was presented in the form of tables and graphs.

\section{Results and Discussions}

\subsection{Gender}

Result in Figure: 1 showed that, two thirds of the respondents' sample (66\%) is made up of males. This result was in line with Jasim et al. (2018), who found that, $64.28 \%$ of park visitors were males. Also, Sufian, (2010) found that $(75.50 \%)$ of respondents were males. This may be attributed to that, women in Sudan are heavily involved in house responsibility (preparation of food, revising lessons with kids etc)

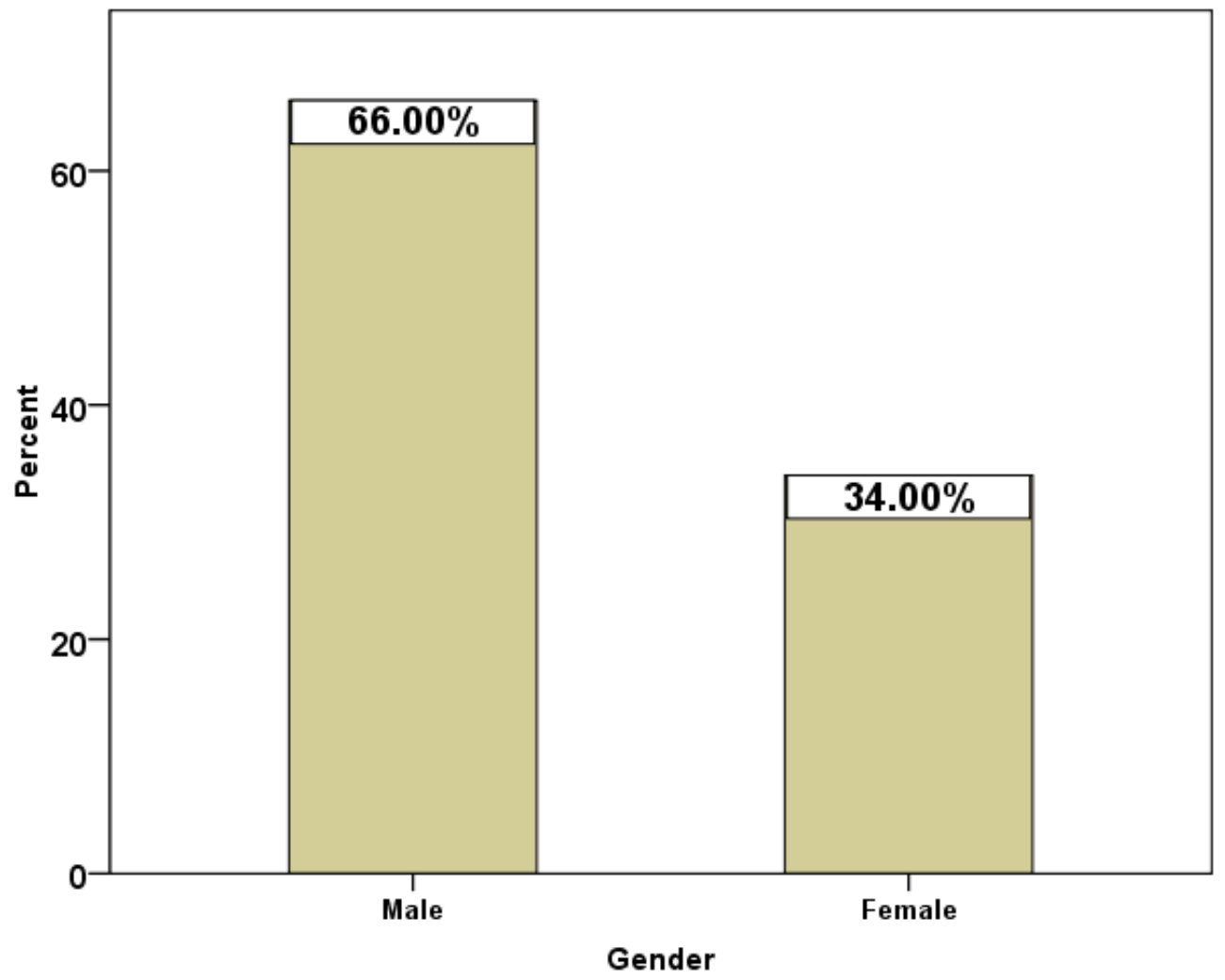

Fig. 1: Gender of El Hurea Yard Park respondents

Source: own calculations from survey data 2019

\subsection{Age}

Figure 2 showed that, the highest percentage of respondents $(73 \%)$ are in the age category of 18 24 years and (18\%) of respondents in the range 25-34 years. It seems that, the majority of responses represent the opinion of youth and young adults, as more than ninety percent of respondents $(91 \%)$ identified themselves as being less than 35 years. this result agreed with Jasim et al. (2018) who revealed 
that, $(60 \%)$ of respondents are in the age category of $15-25$ years, and $(28.57 \%)$ of them are in the age category of 26-34 year. (I.e. more than three quarters of respondents (89\%) identified themselves as being up to 35 years. Also, Wafa, (2015) found that, about half of respondents (49\%) were under the age of 30 years. The lowest percentage $(1 \%)$ is in the age category $65-75$ years, indicating that, this park is not attractive to elders and in our culture visiting parks is associated with young people).

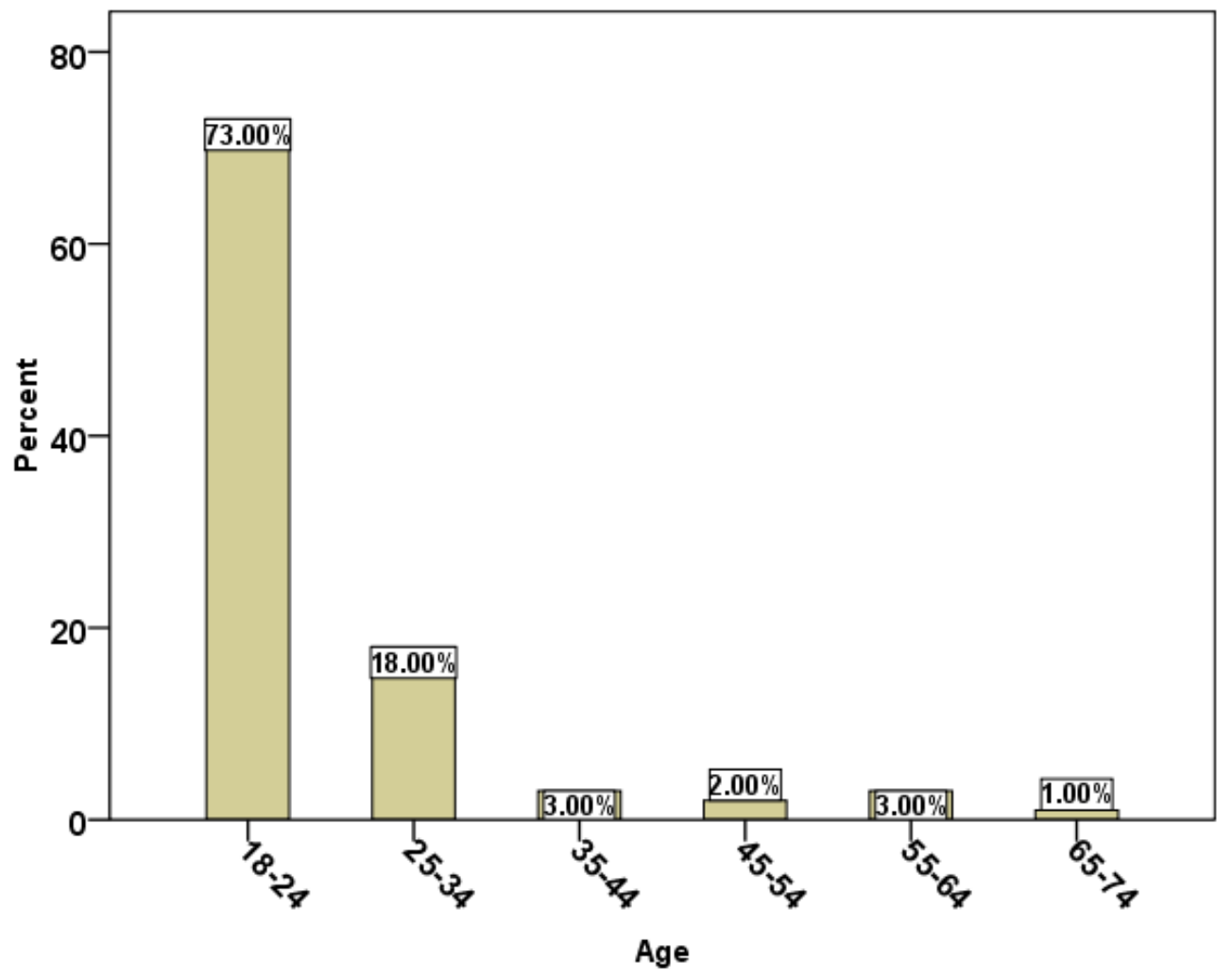

Fig. 2: Age of respondents of El Hurea Yard Park

Source: own calculations from survey data 2019

\subsection{Educational level}

Results in figure 3: indicated that, $(83 \%)$ of respondents were university educated (72\% graduates and $11 \%$ post graduates), this result was in line with Wafa, (2015) who stated that, $(88.4 \%)$ of respondents have university education. Also, Nour et al. (2014), found that, most of park visitors (64\%) have university education. Low ratio of respondents was either can read and write $(2 \%)$ or have preliminary education $(1 \%)$. On the other hand, there is no representation to the illiterate or khallwa education, this may reflect the cultural differences between respondents.

\subsection{Occupation}

Analysis of the survey data indicates that, two thirds of respondents $(66 \%)$ were students $+(4 \%)$ Unemployed. It is clear that, $70 \%$ of respondents were still family dependent, this result was in line with Nour et al. (2014) finding who declared that, most of respondents (56\%) are not working, and he assumed that, they are the women came to the park to entertain their children. this may be attributed to the fact that, at the time of questionnaire distribution, all the Sudanese schools and universities were closed

Special sector employees (1\%) and Labor (3\%) categories, have the lowest park visits this may be due to their heavily involvement in work. 


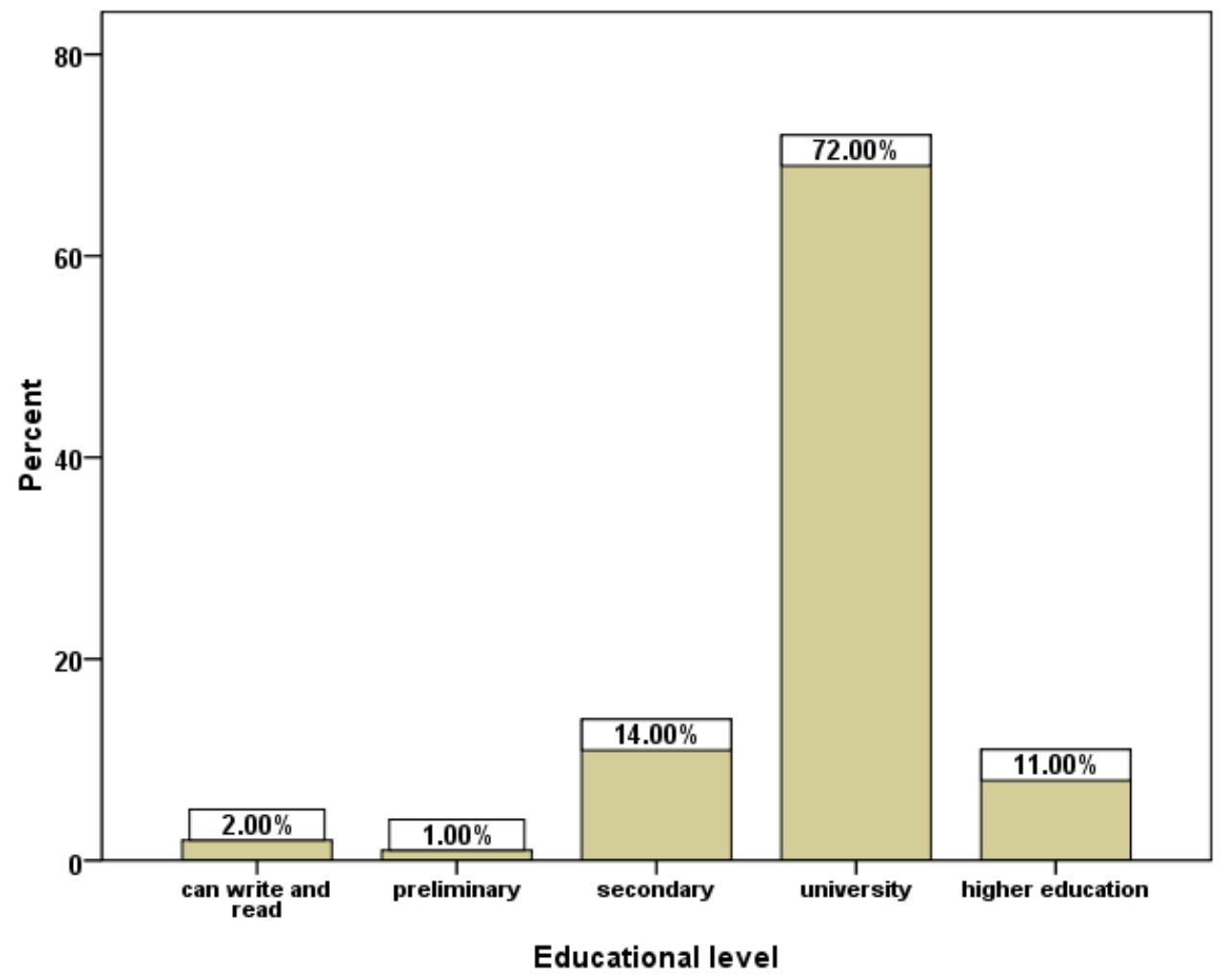

Fig. 3: Educational level of El Hurea yard park respondents Source: own calculations from survey data 2019

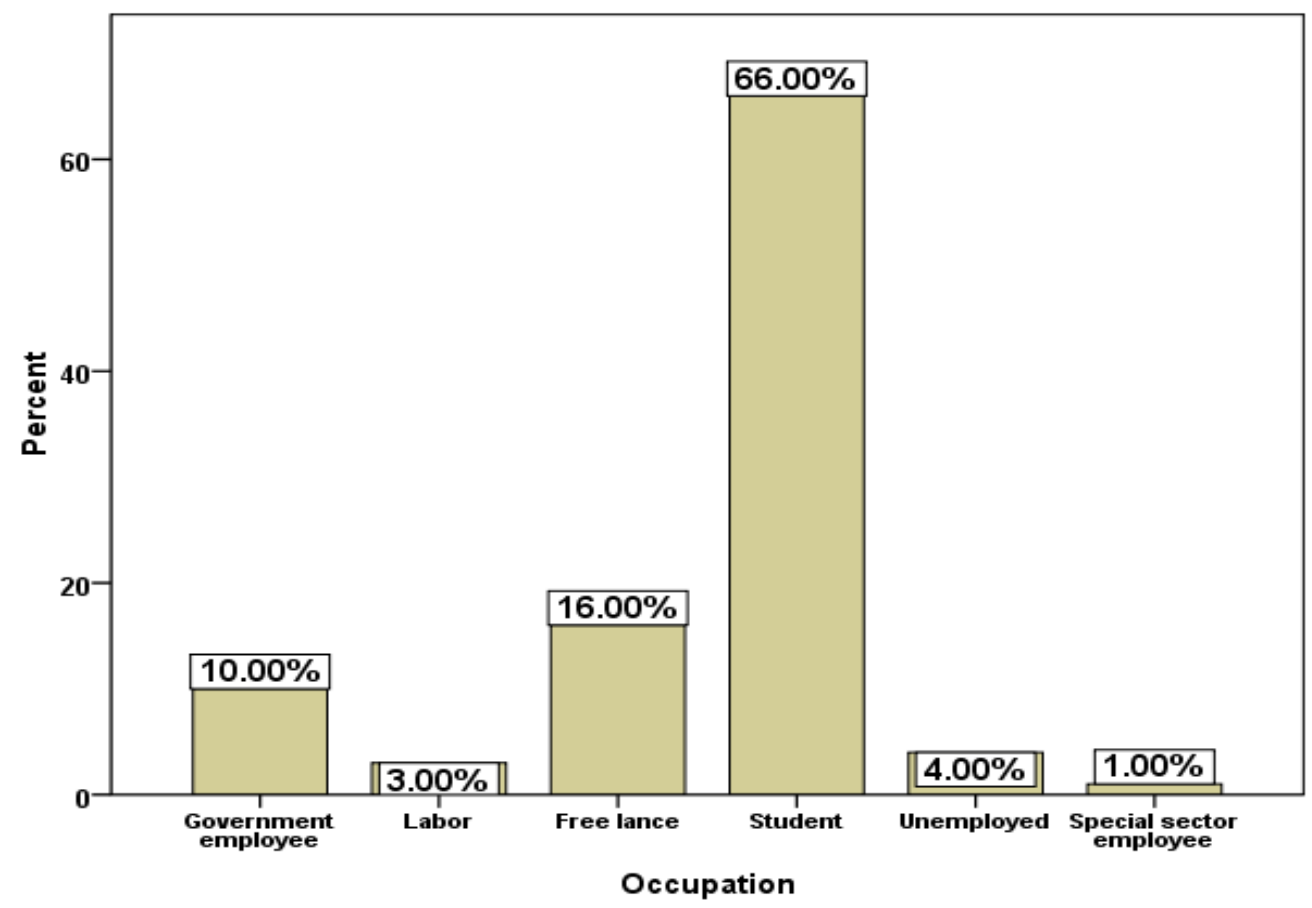

Fig. 4: Occupation of El Hurea yard park respondents Source: own calculations from survey data 2019 


\subsection{Monthly income}

Table 1, showed amazing result, that, the highest percentage of respondents $(70 \%)$ in monthly income category (none), who are still family dependent. This means that, visiting the park is not expensive. On the other hand, the highest monthly income category in income stratum of more, than 10,000 SDG, have the lowest park visits $(5 \%)$, it seems that, they have own means of recreation.

Table 1: Monthly income of El Hurea yard park respondents

\begin{tabular}{lc}
\hline Monthly income & Frequency \\
\hline Non & 70 \\
Less than 1,000 Sudanese pounds & 10 \\
$\mathbf{1 , 0 0 0 - 5 , 0 0 0}$ Sudanese pounds & 7 \\
$\mathbf{5 , 0 0 1 - 1 0 , 0 0 0}$ Sudanese pounds & 8 \\
More than10,000 Sudanese pounds & 5 \\
Total & 100 \\
\hline
\end{tabular}

Source: own calculations from survey data 2019

\subsection{Place of birth}

Results in figure (5) showed that: More than three quarters of respondents $(81 \%)$ born in urban areas.

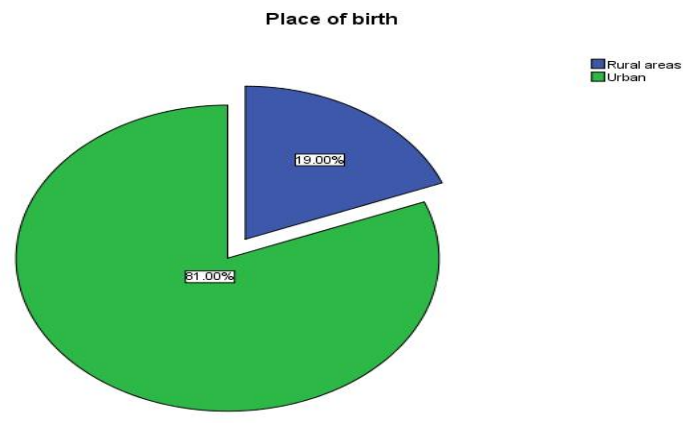

Fig. 5: Place of birth of El Hurea yard park respondents Source: own calculations from survey data 2019

\subsection{Marital status}

Results in figure (6) showed that: More than three quarters of respondents (84\%), are Bachelor.

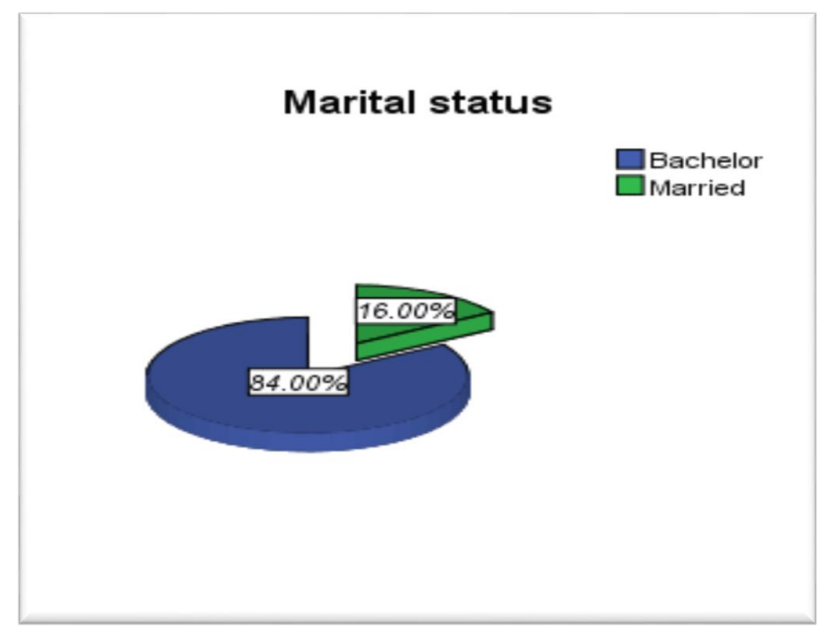

Fig. 6: Marital status of El Hurea yard park respondents

Source: own calculations from survey data 2019 


\subsection{Where respondents live}

The result revealed that: More than (4) in (5) respondents, are from Khartoum city, the same results were recorded by (Wafa, 2015) who found that, most of respondents $(83.2 \%)$ live in Khanyounis city (the center).

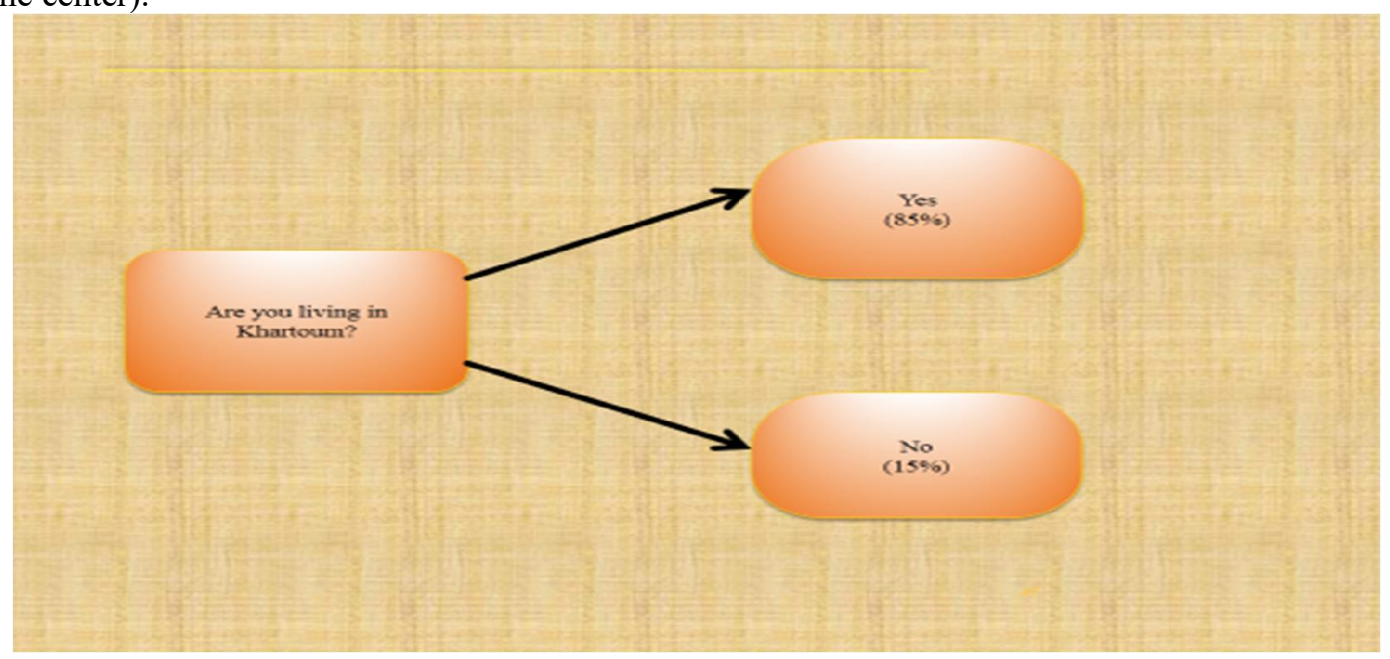

Fig. 7: Are you living in Khartoum city?

Source: own calculations from survey data 2019

\subsection{How far is the Khartoum residents' respondents from the park}

(74\%) of respondents (who live in Khartoum) need 15 minutes to more than 1hour walk to reach the park. More than half of Khartoum resident's respondents (55\%) can reach the park after more than one hour walk. On the other hand, $(22 \%)$ and $(10 \%)$ of them can reach in 31 minutes to hour walk and 15 to 30 minutes' walk respectively. Only, (13\%) of them reside nearby to the park and can easily reach the park in less than 15 minutes' walk.
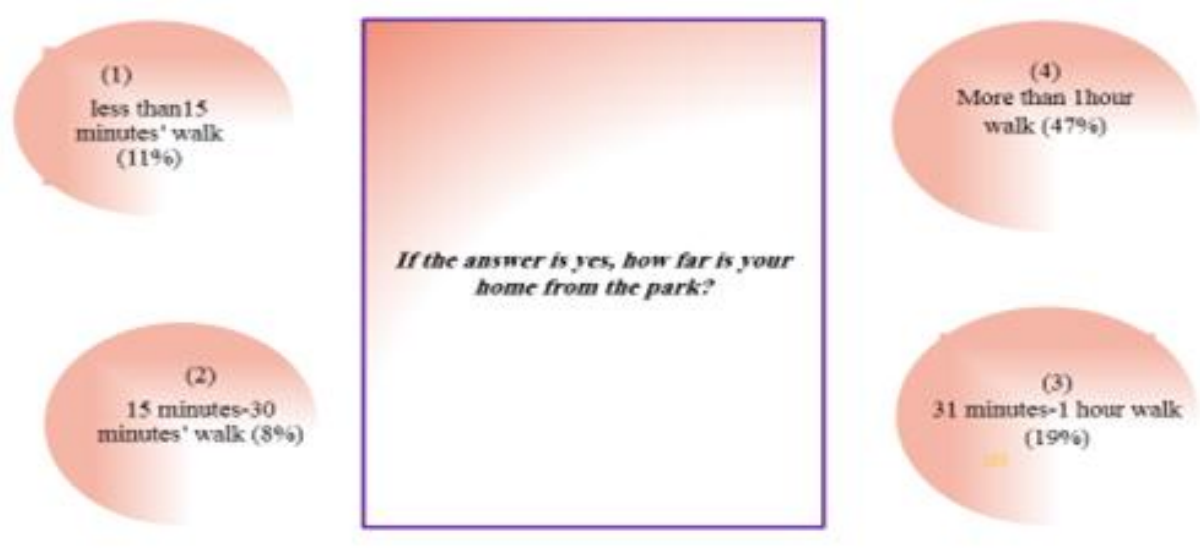

Fig. 8: How far is the Khartoum residents' respondents from the park

Source: own calculations from survey data 2019

3.10. If the answer is one of the last three answers, is there a public garden in respondent's area:

(61\%) of respondents, who live away from the park (more than 15 minutes' walk), have no public garden in their areas. $(39 \%)$ who have other alternatives prefer to visit this park, This, may be due to the smallest size of their public garden or to the unavailability of some services. as analyze (Nour et at. 2014) who found that (56\%) of park respondents, have public gardens in their resident areas. 


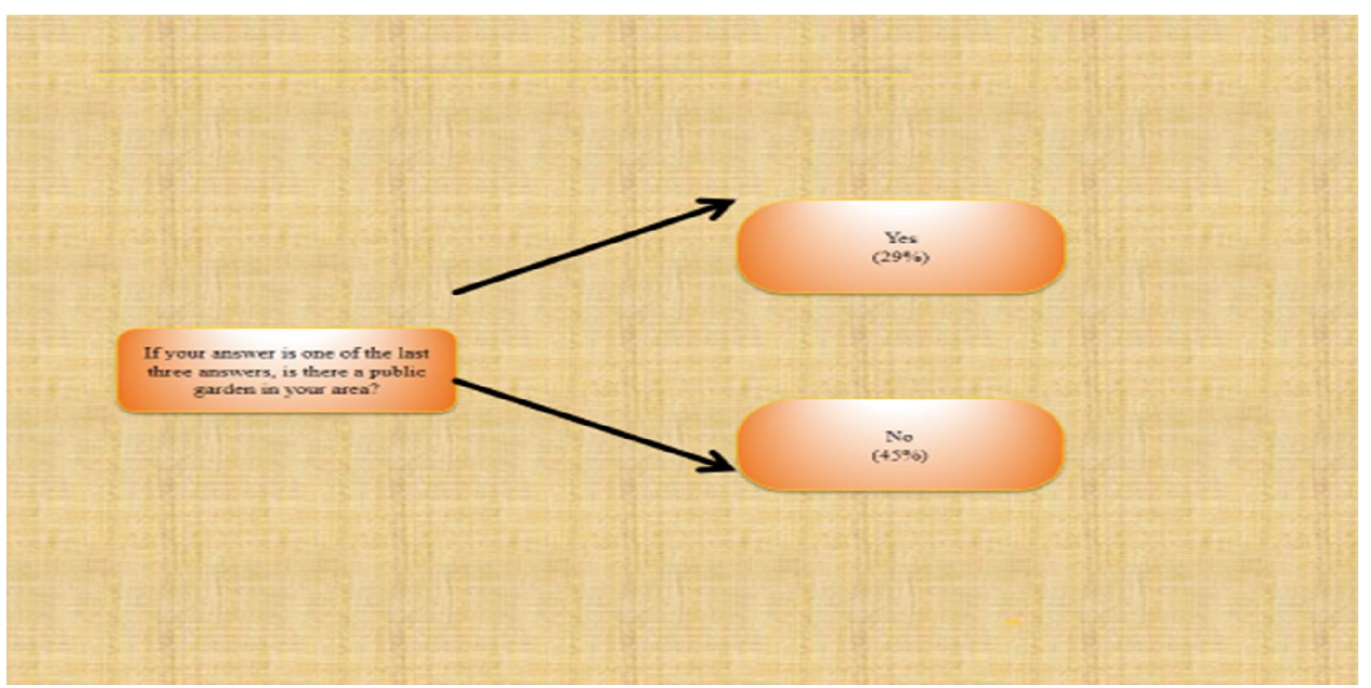

Fig. 9: If the answer is one of the last three answers, is there a public garden in respondent's area Source: own calculations from survey data 2019

\subsection{If respondents are not living in Khartoum city, are you from Khartoum State and why they} are there

Respondents who are not from Khartoum city and not from Khartoum state (7\%), came to the capital for visit, studying, job or mission in government offices.

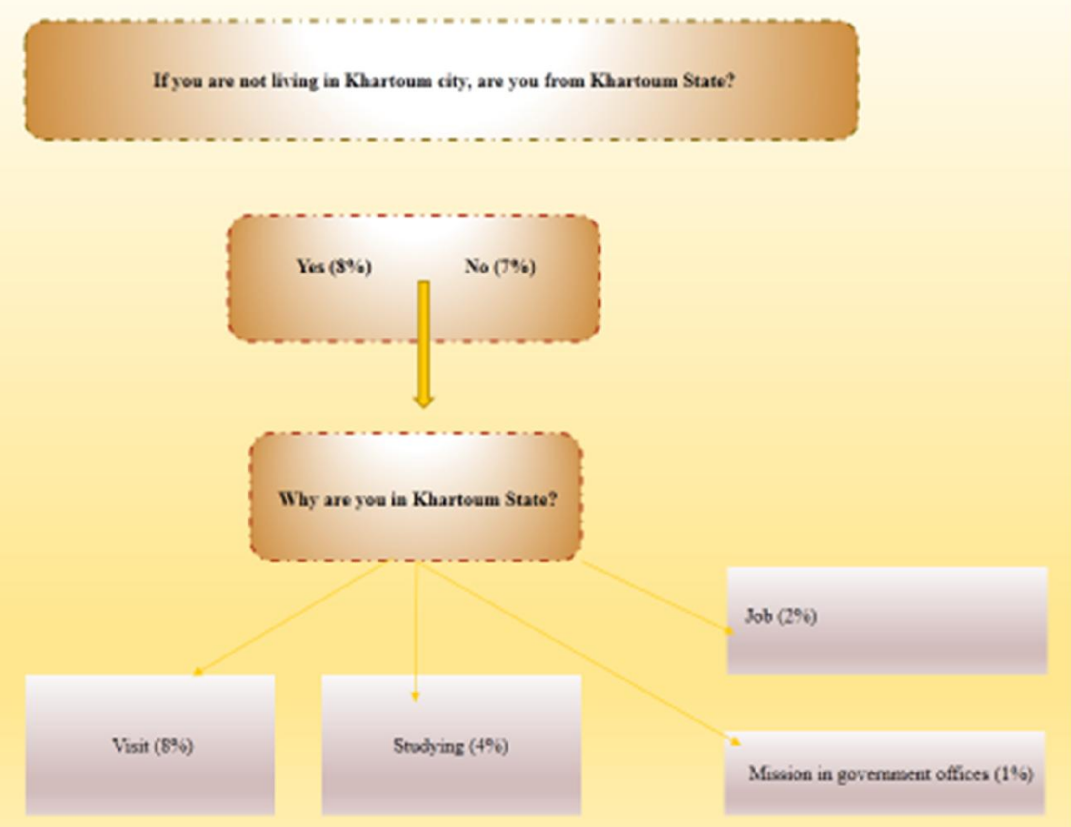

Fig. 10: If respondents are not living in Khartoum city, are you from Khartoum State and why they are there?

Source: own calculations from survey data 2019

\subsection{Division of respondents groups}

The analysis of the questionnaire found that, $(97 \%)$ of respondents go to park in accompany, this result was in line with (Nour et al., 2014) who found that, $(88 \%)$ of respondents go to park in accompany. Also many researchers reported that, parks represent a democratic forum for citizens and society, they provide meeting places and bring communities together, thus they increase social 
interaction and integration among neighbors and shape the cultural identity of the area. (Coley et al., 1997; date; Kuo and Francis, 2001; Baulkwill, 2002; Hagelskamp, 2003).

Interestingly, this result showed that: one third of respondents (33\%) go to the park in companion with: Colleagues $(23 \%)$, family members $(7 \%)$ and relatives $(3 \%)$. On the other hand, the other two third of them (64\%), go to the park in companion with all the mentioned categories. On contrary Sufian, (2010) reported that, $(61.30 \%)$ of respondents go to the park alone.

\subsection{What respondents do in the parks}

Visitors in the park can enjoy a wide variety of community activities and recreational pursuits. Respondents were asked to indicate the activities they under take and they were given 13 categories to choose from. The results showed that, respondents tend to engage in multiple activities. $(92 \%)$ of respondents enjoy using the parks for: enjoying the outdoors or nature and meet relatives, friends and neighbors. This may be due to that, parks provide a place for people to be engaged together in an activity, this is an important element in developing social cohesion with in a community as Buchan, (2007) stated. Besides (81\%) use picnic and general leisure activities. The basic goals for which (79\%) of respondents go to the park is Sitting, relaxing, leisure, escape from noise, congestion and family problems (As we experienced, in the time less and silent atmosphere of natural environments, visitors can breathe freshair, forget the daily worries and relax, both mentally and physically). (77\%) Participate in family activities. And (71\%) Entertaining children, thus parks help in strengthening the family ties. Also parks provide safe places for children to play and (Cornell and Hadley, 2001), reported that, the senses of challenge and adventure children experience in nature can positively contribute to their development. On the other hand, the least people's motives to visit the park include: Eating meals $(45 \%)$, reading $(38 \%)$, indoor sports $(31 \%)$ and play sports $(28 \%)$. This result was in line with (Reihaneh, (2012), research who found that, the motive most frequently mentioned by the park visitors is to relax (81\%), to be in nature (58\%), to be with the children (47\%) and to sport (34\%). The indoor sports and play sports gained the least importance, although (WHO, 2016), revealed that; beneficial health effects of parks include: reduction in cardiovascular morbidity; mortality; obesity; risk of type 2 diabetes and improved mental health and pregnancy outcomes. Also it is stated that, access to parks has been associated with reduced stress levels (Ulrich 1981; Hartig et al., 2003; Grahn 2003; Mass et al., 2006; Nielsen, 2007), reduced depression (Morita et al. 2007) and positively influenced the longevity of urban senior citizens (Takano et al., 2002).

\subsection{Frequency of visiting the parks}

Respondents were asked to categorise their involvement in the park, from frequently (Once a week or more), sometimes (1-2 times a month) to rarely (Less than 5 times a year). The results showed that: nearly, two third of respondents $(63 \%)$ have frequent visits, $(20 \%)$ of them sometimes visit the park and (17\%) have a rare park visits. As (Sada et al. 2018) results, where (74.4\%) of respondents have frequent visits to the park. (Paraskevi, 2016) indicated that, frequent and longer visits of parks significantly improved resident's well-being.

\section{Conclusions and Recommendations}

Visitng parks in Sudan is easy and not expensive. Parks are places for sport activities, but it is unused. Elder representaion in the park is very week, so attention should be paied to attract this community group. Attention should be paid to the public gardens, to serve the nearby visitors and to reduce stress on the parks.

Park's design and management, should take into account recreational requirements of all visitors. Recently, parks in Sudan gain greater popularity and most of the social occasions occairs in parks and gardens. Sudan is rich in elements needed for parks develpement, researches and governmetal efforts are much needed.

\section{References}

Al-Berta Culture and Tourism. Final Report, 2017.

Baulkwill, A., 2002. Lots of conviviality. The Garden, 693-697. 
Buchan, and Dianne, 2007. Not Just Trees in the Ground: The social and economic benefits of community-led conservation projects.

Coley, R., F. Kuo, and W. Sullivan, 1997. Where does community grow? The social context created by nature in urban public housing. Environ. behav., 29: 468-494.

Cornell, E.H., and D.C. Hadley, 2001. Adventure as stimulus for cognitive development. J. Environ. Psychol., 21: 3 .

Grahn, P. and U. Stigsdotter, 2003. Landscape Planning and Stress, Urban Forestry Urban Greening, 2: $1-18$.

Hagelskamp, C., 2003. Please touch: How Aachen'spublic art adds to its public life. Project for Public SpaceNewsletter. Availablefrom:http://pps.org/info/newsletter/Sep_2003/Sep2003_Aachen.

Hartig, T., G.W. Evans, L.D. Jamner, D.S. Davis, and T. Garling, 2003. Tracking restoration in natural and urban field settings. Journal of Environmental Psychology, 23: 109-123.

Kuo, F.E. and E. Frances, 2001. Green streets, Not mean streets. University of Illinois at Urbana Champaign. Human- Environment Research Laboratory, 33(3): 343- 367.

Luttik, J., 2000. The value of trees, water and open paces as reflected by house prices in the Netherlands\&\#39;. Landscape and Urban Planning, 48: 161-167.

Maas, J., R.A. Verheij, P. Groenewegen, S. de Vries, and P. Spreeuwenberg, 2006. Green Space, Urbanity, and Health: How Strong is the Relation?. Journal of Epidemiology Community Health, 60: 587-92.

Morita, E., S. Fukuda, J. Nagano, N. Hamajima, H. Yamamoto, Y. Iwai, T. Nakashima, H. Ohira, and T. Shirakawa, 2007. Psychological Effects of Forest Environments on Healthy Adults: ShinrinYoku (Forest-Air Bathing, Walking) as a Possible Method of Stress Reduction. Public Health, 121: 54-63.

Nielsen, T.S., and K.B. Hansen, 2007. Do Green Areas Affect Health? Results from a Danish Survey on the Use of Green Areas and Health Indicators. Health Place, 13: 839-850.

Nour S., S. Ghasan and E. Naabeel 2014. Assessment the asppects of service, environment and aesthetics of the public garden at new sham suburb. Journal of Demascus University for Agricultural Sciences. 30(1): 9-28.

Paraskevi, K., P. Thomas, T. Stilianos, and K. Aikaterini, 2016. A perceptual study of users' expectations of urban green infrastructure in Kalamaria, municipality of Greece. Management of Environmental Quality, 27(5): 568-584.

Peiser, R.B. and G.M. Schwann, 1993. The private value of public open space within subdivisions. Journal of Architectural and Planning Research, 10(2): 91-104.

Reihaneh Sadat Hajmirsadeghi, 2012. Elixir Sustain. Arc. 51: 10766-10770.

Robert, E.M. and A.F. Wayne, 2017. Use of Visual Research Methods to Measure Standards of Quality for Parks and Outdoor Recreation. Pages 557-579. Published online: 13 Dec 2017.

Sada, N.J., M.A. Ali, and R.Z. Miasar, 2018. Study the Reality of the Park Between the two Bridged in Baquba City (Mabain Aljesrain). Diyala Journal of Agricultural Sciences, 10(2):79-86. http://www.agriculmag.uodiyala.edu.iq/

Suad, K.A. and E.Y. Mahmood, 2021. The Important Roles of Parks and Gardens in the Quality of Life. Middle East Journal of Agriculture Research, 10(3): 937-944.

DOI: $10.36632 / \mathrm{mejar} / 2021.10 .3 .60$

Sufian, B., 2010. The public gardens in the urban environment in Ghustantina - field study in Basheer Bn Naseer garden. University of Muntoori, Faculty of human and Social Sciences, Department of Social Science, Ghustantina.

Takano, T., K. Nakamura, and M. Watanabe, 2002. Urban residential environments and senior citizens longevity in megacity areas: the importance of walkable green space. Journal of Epidemiology and Community Health, 56(12): 913-918. https://www.jstor.org/stable/25569881.

Ulrich, R.S., 1981. Natural versus urban sciences: some psycho-physiological effects. Environ. Behav., 13: $523-556$.

World Health Organization (WHO), 2016. Urban green spaces and health. Copenhagen: WHO Regional Office for Europe, 2016..

Wafa, N.E. and K.E. Mustafa, 2015.The Impact of Pedestrians Streets on sustainability of Urban Areas Case Study (city Center of Khan younis). Msc.Thesis, Faculty ot Architechural Engineering, The Eslamic University, Gaza. 